ACCEPTED MANUSCRIPT

\title{
Structural and compositional analysis of Co-based coatings after catalytic tests for the sodium borohydride hydrolysis
}

To cite this article before publication: Ana M Beltrán 2019 Mater. Res. Express in press https://doi.org/10.1088/2053-1591/ab1e27

\section{Manuscript version: Accepted Manuscript}

Accepted Manuscript is "the version of the article accepted for publication including all changes made as a result of the peer review process, and which may also include the addition to the article by IOP Publishing of a header, an article ID, a cover sheet and/or an 'Accepted Manuscript' watermark, but excluding any other editing, typesetting or other changes made by IOP Publishing and/or its licensors"

This Accepted Manuscript is @ 2019 IOP Publishing Ltd.

During the embargo period (the 12 month period from the publication of the Version of Record of this article), the Accepted Manuscript is fully protected by copyright and cannot be reused or reposted elsewhere.

As the Version of Record of this article is going to be / has been published on a subscription basis, this Accepted Manuscript is available for reuse under a CC BY-NC-ND 3.0 licence after the 12 month embargo period.

After the embargo period, everyone is permitted to use copy and redistribute this article for non-commercial purposes only, provided that they adhere to all the terms of the licence https://creativecommons.org/licences/by-nc-nd/3.0

Although reasonable endeavours have been taken to obtain all necessary permissions from third parties to include their copyrighted content within this article, their full citation and copyright line may not be present in this Accepted Manuscript version. Before using any content from this article, please refer to the Version of Record on IOPscience once published for full citation and copyright details, as permissions will likely be required. All third party content is fully copyright protected, unless specifically stated otherwise in the figure caption in the Version of Record.

View the article online for updates and enhancements. 


\title{
Structural and compositional analysis of Co-based coatings after
}

\section{catalytic tests for the sodium borohydride hydrolysis}

\begin{abstract}
A.M. Beltrán
Instituto de Ciencia de Materiales de Sevilla (CSIC - Univ. Sevilla), Avda. Américo Vespucio 49, 41092-Sevilla, Spain
\end{abstract}

*Current address: Departamento de Ingeniería y Ciencia de los Materiales y del Transporte. Escuela Politécnica Superior, Virgen de África 7, 41011 Sevilla, Spain

Corresponding authors: abeltran3@us.es

\begin{abstract}
The use of Co-based catalysts for the sodium borohydride hydrolysis for hydrogen production is a well-known process as a source of clean energy, although its mechanisms are still under discussion. With the aim of acquiring a deeper knowledge about this catalytic process, three different catalysts $(\mathrm{Co}, \mathrm{CoC}$ and $\mathrm{CoB})$ were deposited as a thin film layer by magnetron sputtering onto a polymeric membrane, used as a substrate and analyzed by advance transmission and scanning-transmission electron microscopy techniques (STEM). Structural and compositional characterizations, by electron energy loss spectroscopy (EELS), have been performed on the coatings before and after their use as catalysts on the sodium borohydride reaction for 90 minutes, to check the production of hydrogen. Results have shown the formation of $\mathrm{Co}_{\mathrm{x}} \mathrm{B}$ nanoflakes and other Co-based compounds over the catalysts and related to their catalytic activity. Knowing the changes in the structure and composition of the catalysts is key to understanding their catalytic behavior, activity and durability. Among the analyzed catalysts, the $\mathrm{Co}-\mathrm{C}$ presents better activity during the first cycles, which is related to a larger formation of
\end{abstract} $\mathrm{Co}_{\mathrm{x}} \mathrm{B}$

Keywords: Cobalt; hydrogen storage; magnetron sputtering; STEM; EELS 


\section{Introduction}

The use of Cobalt-based catalysts in diverse reactions is a widely explored research field nowadays ${ }^{1-4}$. The fabrication of stable Cobalt-based catalysts are of high interest in different technologies ${ }^{5-7}$. In particular, the generation of Hydrogen via hydrolysis using sodium borohydride $\left(\mathrm{NaBH}_{4}, \mathrm{SBH}\right)$ (see reaction 1), which requires catalysts to occur ${ }^{8}$, exemplifies the utilization of these types of catalysts. The functionality of this kind of catalysts is of high interest in an environmentally respectful future energy carrier with a potentially high impact. So far, Cobalt (Co) has demonstrated to be an interesting candidate to accelerate such reaction, producing Hydrogen at high rates since it shows a good compromise between high activity and low $\operatorname{cost}^{9}$.

$$
\mathrm{BH}_{4}^{-}(\mathrm{aq})+4 \cdot \mathrm{H}_{2} \mathrm{O}(\mathrm{l}) \rightarrow 4 \mathrm{H}_{2}(\mathrm{~g})+\mathrm{B}(\mathrm{OH})_{4}^{-} \quad(\text { reaction } 1)
$$

Diverse nanostructures were proposed for the synthesis of Co-based catalysts ${ }^{10,11}$, even the development of three-dimensional honeycomb-like nanostructures with well-arranged nanoflakes of Co-B have been reported ${ }^{12}$. All these materials are produced as powder and, therefore, present agglomeration-related drawbacks. Efficient solutions to this disadvantage would be the use of an atomic diffusion barrier between the Co-B particles or embedding them on a supported material. Thin-film supported catalysts are also an effective alternative since (i) they present an extra degree of freedom to change the surface morphology and structure; (ii) they can be recovered and reused, and (iii) they can be used as on/off switch for $\mathrm{H}_{2}$ generation $^{13-15}$. Nevertheless, as catalyst, better supporter requires higher surface area, such as carbon, silica, Ni foam and others. The use of porous supports may enhance the catalytic activity. It is possible due to the better dispersion of the active catalyst, easier diffusion of reactants through the pores, improved dissipation of the reaction heat, retarded sintering of the active phase and higher resistance to deactivation ${ }^{14,16}$. 


\section{Materials and Methods}

In view of this statement, better catalysts would be based on the use of thin-film supported by higher surface area materials. In this way, the growth of supported Co catalysts as thin film by magnetron sputtering (MS) is a good option. MS was already reported ${ }^{17}$ as a versatile technique since it allows a high control on the thin-film thickness during its deposition due to the low deposition temperature process. It permits to tailor the morphology, which controls some functional properties and, therefore, the final catalytic properties.

Furthermore, the role of a catalyst is to increase the rate of a chemical reaction and continue its activity as long as possible, but what happens during its use? Although the formation of nanoflakes was reported due to the chemical reaction in diverse catalytic systems, such as CoB nanoparticles ${ }^{18}$, Co-B nanoflakes ${ }^{15}$, Co-B-C composites ${ }^{19}$, NiCo on carbon-nanotubes ${ }^{20}$, they do not show evidences of the formation of preferential stable compounds ${ }^{21}$.

This work presents the structural and compositional analysis by the combination of diverse transmission and scanning-transmission electron microscopy ((S)TEM) techniques before and after the catalytic test to evaluate the effect of reaction (1) on the structure and composition of Co-based thin film catalytic coatings grown by MS. Cobalt-Carbon (Co-C) and Cobalt-Boron (Co-B) catalysts were also evaluated in order to explore the role of these amorphous materials. The structural and compositional evolution of Co-based catalysts before and after the SBH has been characterized. Compositional nanometric analyses revealed the formation of $\mathrm{Co}_{x} \mathrm{~B}$ nanoflake-like structures onto the three catalytic coatings (Co, Co-C, Co-B) after the SBH hydrolysis (reaction 1) for 90 minutes. The studies summarizes in this work are highly novel. Although seyeral works have reported the fabrication of different coatings and their catalytic tests, the novelty of this work lies on the deeper nanocompositional studied, included the microscopy of the used catalysts, helping to understand the mechanism of the catalytic reaction and to propose the design of better catalysts. 
Three different thin-films, each one using a different metallic catalytic coating $(\mathrm{Co}, \mathrm{Co}-\mathrm{C}$, Co-B), were grown by MS. For the preparation of the coatings by MS, 2" diameter target was employed using a pure targets of the three elements (Cobalt: Kurt J. Lesker, $99.95 \%$ pure, 1 mm thick; Boron: Kurt J. Lesker, $99.95 \%$ pure and Carbon: Kurt J. Lesker, $99.99 \%$ pure). Details about the whole procedure have been reported ${ }^{22}$. The thin-films were deposited on a composed supporting material, Polytetrafluoroethylene (PTFE) membranes, which were deposited on a Polyethylene mesh (Pall Corporation PTF002LH0A-SAMP, $0.02 \mu \mathrm{m}$ pore'size, polypropylene backed). The fibers of the polymer confer a high porous structure with a large surface area, so it is very suitable for catalytic test. The description of the samples and the corresponding MS deposition parameters are presented in Table 1?

Table 1: Sample labels and deposition parameters.

\begin{tabular}{|c|c|c|c|c|c|}
\hline \multirow{2}{*}{ Sample label } & \multicolumn{3}{|c|}{ Power (W) } & $\begin{array}{c}\text { Deposition pressure } \\
\left(\mathbf{1 0}^{-2} \mathbf{m b a r}\right)\end{array}$ & $\begin{array}{c}\text { Deposition time } \\
\text { (min) }\end{array}$ \\
\cline { 2 - 4 } Co & C & B & 4.5 & 60 \\
CoC & 50 & - & -2.8 & 60 \\
CoB & 50 & 100 & - & 2.8 & 90 \\
\hline
\end{tabular}

These three samples were characterized before and after the catalytic test in order to determine the differences in the structure and the composition induced by the SBH hydrolysis (reaction 1). Catalytic tests were performed on the coating, without removing it from the supporting PTFE substrate, at 19 wt. \% SB in 4 wt. \% $\mathrm{NaOH}$, and for 90 minutes of reaction time. This direct measurement is quite convenient, though, it also makes the TEM analyses of these systems (supporter plus catalyst) quite challenging, due to the instability of the substrate under the electron beam and the difficulty to prepare TEM lamellas. More details about the catalytic test and additional measures can be found in a reference ${ }^{22}$.

Nano-characterization by (S)TEM techniques requires firstly the preparation of electron-transparent lamellas. When catalytic coatings are deposited on a polymeric substrate, 
the standard procedure of TEM sample preparation cannot be applied. Focused ion beam is neither a good alternative since the substrate melts during the preparation process and deposits over itself. However, during this work, it was possible to separate the PTFE membrane from the polypropylene back-support and glue it to a conventional copper frame grid. After that, the coated PTFE membrane was milled to electron transparency using $\mathrm{Ar}^{+}$beams accelerated at 1-3 $\mathrm{kV}$ in a model 1010 Fischione Instruments Ion Etching Milling system. In this context, it is worth to mention that besides the difficulties of preparing a thin TEM lamella, the polymer supporter is also not very stable under the electron beam. Then, observing an electrontransparent area implies a careful search of the thinnest and more stable zones. Therefore, the quality of the TEM results are affected by the thickness of the observed regions.

The applied (S)TEM techniques consisted in both Conventional TEM in Diffraction Contrast mode, to obtain Bright Field TEM (BF-TEM) micrographs, and STEM imaging and spectroscopy, such as atomic-mass contrast imaging (high angle-annular dark field, HAADF) and energy-loss spectroscopy (EELS), unable to perform the chemical and electronic analysis of a material with a spatial resolution below $1 \mathrm{~nm}$, while maintaining a sub-eV energy resolution ${ }^{23}$. It is worth to mention that the intensity in HAADF images is proportional to $t \cdot Z^{n}$, where $t$ represents the specimen thickness crossed by the electron beam and $\mathrm{Z}$ is the averaged atomic mass of the material that interacts with the electron beam, with $n$ ranging between 1.6 and 1.9 in most cases ${ }^{24}$.

These techniques were carried out in a Field Emission Gun (FEG) FEI Tecnai G2 F30 S-Twin high-resolution transmission electron microscope with scanning-TEM capabilities operating at $300 \mathrm{kV}$, available at the Laboratory of Nanoscopies and Spectroscopies (LANE-ICMSE, Sevilla, Spain). This microscope spatial and energy resolutions are $0.2 \mathrm{~nm}$, in TEM images, and $0.8 \mathrm{eV}$, when using EELS. This resolution is measured by the full-width at half-maximum (FWHM) of the zero-loss peak. The microscope is equipped with a HAADF detector, with $0.16 \mathrm{~nm}$ spatial resolution, from Fischione Instruments. The used convergence and collection semi-angles were 
12.4 and $9.6 \mathrm{mrad}$, respectively. Spectra acquisition and processing were done with GATAN Digital Micrograph Suite ${ }^{25}$ with a pixel size of $1 \mathrm{~nm}$ using subpixel scanning (16 x16). EELS were acquired in the Core-Loss (CL) region with a dispersion of $0.5 \mathrm{eV} / \mathrm{channel}$ and acquisition time about 2 s. After each CL spectrum, a Low-Loss (LL) EELS was also acquired in the same region, with an energy dispersion of $0.05 \mathrm{eV} / \mathrm{channel}$ and shorter acquisition time, usually below $0.5 \mathrm{~s}$ to determine the thickness of the analyzed area as well as use the Zero-Loss peak as a reference to reduce the multi-scattering of the CL-EELS in the attempt to minimize the effect of the thickness on the chemical analyses. The main objective for the acquisition of spectrum images (SIs) was to obtain precise local compositional information from small areas (about 4 $9 \mathrm{~nm}^{2}$ ) of the samples, before and after the catalytic test. EELS-SI mode benefits from high spatial resolution TEM, while maintaining a good energy resolution. The spatial drift correction was applied during the SI recording and dark current effects were removed from the EELS data using DM-GATAN software. In order to integrate EELS signals, backgrounds were adjusted to a power law function.

\section{Results and Discussion}

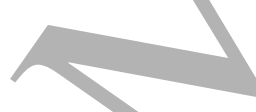

Fig. 1a-c show three BF-TEM micrographs corresponding to the samples in Table 1, supported on a PTFE substrate, before the catalytic test. The three Co-based coatings covered the fiber of the polymer and presented a columnar structure, which is the typical morphology of these systems for the chosen MS deposition parameters. The structure was mesocolumns formed by the association of nanocolumns ${ }^{26}$, revealing certain porosity among them. The size of the nanocolumns of the three studied samples were very similar. The introduction of C or B did not modify the nanocolumnar structure of the samples, it only affected to their crystallinity, increasing the amorphization. It was already observed in previous works where it was confirmed that the Co metallic phase were hexagonal (hcp), although certain cubic structure could not be disregarded ${ }^{22}$. 

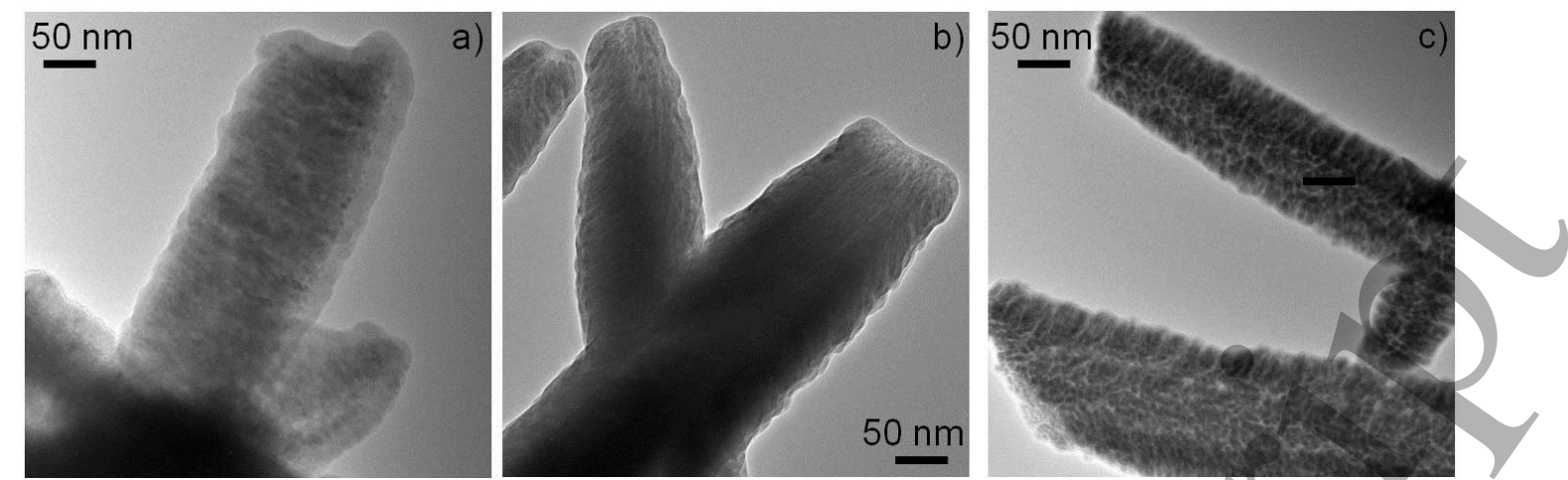

Figure 1: BF-TEM images of thin film before the catalytic test on a PTFE substrate a) $\mathrm{Co}, \mathrm{b}$ ) $\mathrm{CoC}$ and c) CoB.

After 90 minutes of the catalytic test, changes on the morphology aspect were clear. The generation of nanoflakes on the catalyst films was observed. However, the nanocolumnar structure was still visible on the three coatings as it is shown in the HAADF images of the Fig. 2a-c. From the microscopic point of view, there were no differences among the three coatings. After the reaction, the open pores were kept, which is favorable for the catalytic activity. However, the increase of the thickness of the TEM lamella (due to the generation of nanoflakes around the thin film coatings) made difficult to obtain good diffraction patterns that would allow analyzing the crystal structure of the material. The fact that the nanocolumnar structure and the pores remains suggests that the crystallinity should be also the same, hexagonal with certain cubic structure, as it has been above-mentioned, and Co-C and Co-B less crystalline.
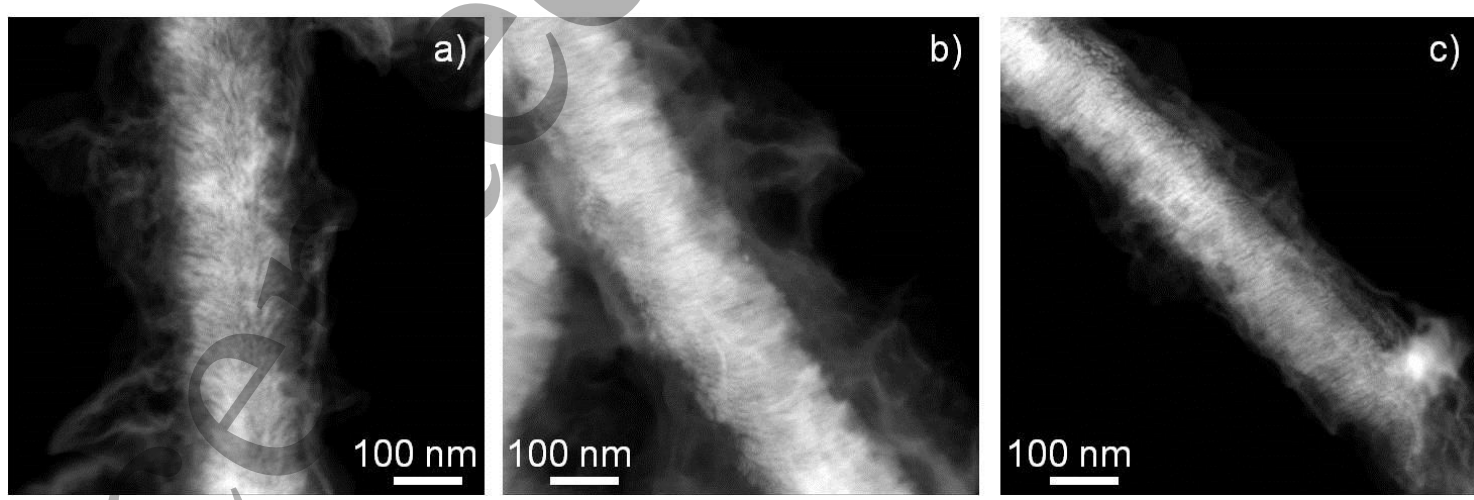

Figure 2: STEM images of thin film on a PTFE substrate after the catalytic test a) $\mathrm{Co}, \mathrm{b}) \mathrm{CoC}$ and c)

rar


The composition is a key factor to be determined in order to know the role of the incorporation of B and C. Among the different available techniques for compositional characterization, this work is focused on EELS analyses. These techniques allow evaluating compositional modifications during the SBH hydrolysis with the advantages of work on the same substrate for the fresh and used samples (PTFE substrate is able to perform the catalytic tests). Due to thickness effects (that could not be avoided due to the TEM lamella preparation and which was even increased after the formation of nanoflakes), EELS spectra presented strong contributions from multi-scattering, which prevented from extracting the fine-structure from them. Table 2 summarizes the compositional distribution for the three samples before ("fresh") and after ("used") the catalytic test. Focusing on the "fresh" data, the detected elements and the shape of the edge corresponded to the expected results for these samples. The measured values of fresh samples could be associated to typical stoichiometries of Co-C and Có-B samples. In addition, they mostly agreed with Rutherford Back-Scattering (RBS) measurements on fresh samples on Si substrates ${ }^{22}$ (the slight differences might be attributed to the different substrates since RBS were performed on coatings deposited on a Silicon wafer and EELS on PTFE substrates). The formation of Cobalt oxides $\left(\mathrm{CoO}\right.$ and $\left.\mathrm{Co}_{3} \mathrm{O}_{4}\right)$ were also present on the materials because oxidation may occur during the preparation of the TEM lamella and/or during the observation in the microscope, due to the high-energy electron beam. It is even possible that oxidation happened during the deposition of the coating, which can be greater on the pores between columns.

The catalytic reaction led to the formation of Co-borates as it was confirmed by the increment of $\mathrm{B}$ and $\mathrm{O}$ detected, together with a decrease of $\mathrm{Co}$, respect to the fresh samples. It has been already reported that at the beginning of the reaction, an excess of $\mathrm{BH}_{4}{ }^{-}$in solution is responsible for oxidized cobalt species, such as $\mathrm{Co}(\mathrm{OH})_{2}$, to be reduced to $\mathrm{Co}_{2} \mathrm{~B}$, which is the active catalytic phase ${ }^{27}$. Furthermore, it is also known that the Co-B compound acts as very active catalyst for $\mathrm{H}_{2}$ generation during hydrolysis of $\mathrm{NaBH} 4$ as compared to most of precious 
metals catalyst $\mathrm{t}^{28}$. Therefore, the presence of this compound can be considered very positive for the catalytic activity of the catalyst.

Table 2. Average elemental distribution of the coatings (at. \%).

\begin{tabular}{|c|c|c|c|c|c|}
\hline \multirow{2}{*}{ Sample } & Sample state & Co (at. \%) & C (at. \%) & B (at. \%) & O (at. \%) \\
\hline Co & Fresh & 90 & 0 & 0 & 10 \\
& Used & 63 & 0 & 12 & 25 \\
CoC & Fresh & 85 & 8 & 0 & 17 \\
& Used & 52 & 4 & 27 & 16 \\
CoB & Fresh & 69 & 0 & 15 & 24 \\
\hline
\end{tabular}

After the catalytic test, new compounds appeared on the coating, even in the case of the sample of pure Co, due to the formation of nanoflakes during the reaction. In this sense, localized EELS and/or ELNES analyses are interesting for these samples, not only because of the details about the composition, but also due to the information about the nature of the compounds. Attention is focused on B and Co edges, which are shown in Fig. 3a and 3b, respectively, for the whole set of samples. As it has been previously mentioned, the thickness of the TEM lamellas makes ELNES analyses particularly challenging. However, any information related to the composition of the catalysts after the catalytic reaction is quite helpful to understand the mechanism.

Fig. 3a shows the B-K edge of the CoB "fresh" and all the "used" samples. B-K edge analysis was highly affected by the TEM lamella thickness, even when it was minimized by removing the plural scattering, since this edge is located close to the lower energy of the CL area and some residual signal from the LL region can be still present in the spectra. In spite of this artifact, the B-K edge was observed. For $\mathrm{CoB}$ and $\mathrm{CoC}$ "used" samples, the shape of the edge resembled the combination of a sharp and broad peak together, which corresponds to B-compounds. In fact, the fine structure of the B-K edge of $\mathrm{CoB}$ and other borides is very 
$\operatorname{similar}^{23,29,30}$. According to that, and taking into account that oxygen is also present, the B-K edge can be considered a combination of the fine structure of $\mathrm{Co}_{\mathrm{x}} \mathrm{B}$ and $\mathrm{Co}\left(\mathrm{BO}_{2}\right)_{2}$. The sharpest B edge on Co-C catalyst would explain the increase in activity detected after the first use. In the case of Co "used" sample, the presence of B cannot be disregarded with the present data. All these results are in agreement with previous works on similar material ${ }^{22}$.

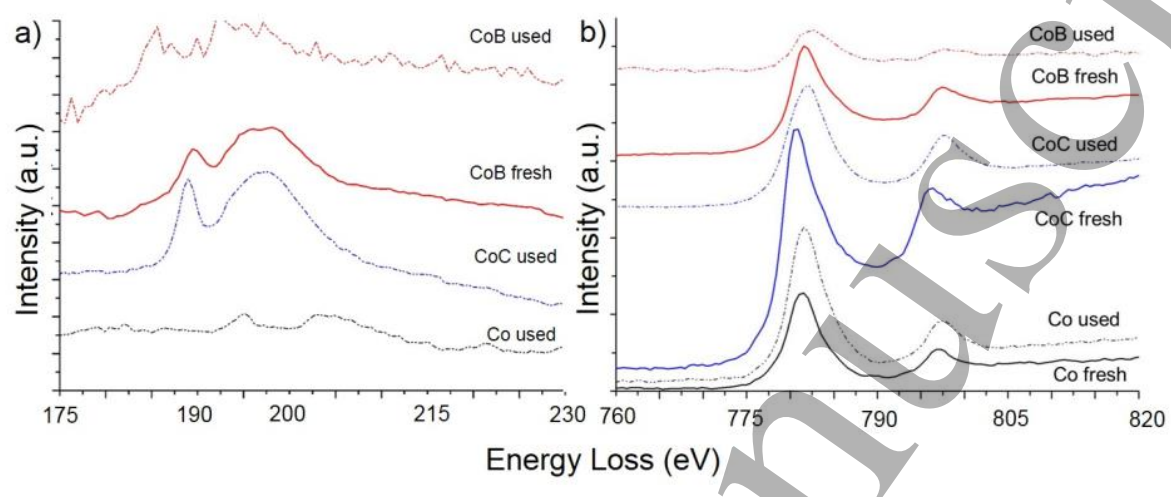

Figure 3: EEL Spectra for the different samples a) B-edges and b) Co-edges.

Normalized Co $\mathrm{L}_{2,3}$ edges for the six samples ("fresh" and "used" samples) are shown in Fig. 3b. Some peak shift was expected on the Co-edge due to the different compounds present on the samples. These shifts correspond to the electronic transitions from orbital $2 p$ to $3 \mathrm{~d}$, which indicate the existence of unoccupied states in the d-band ${ }^{31}$. EELS studies of Co fresh sample revealed the presence of metallic Co, although oxides were also presented, which slightly modifies the typical shape of the Co $\mathrm{L}_{2,3}$ edge. In the case of the CoC "fresh" sample, the changes in the Co peak shape indicated the presence of Co-oxides $\left(\mathrm{CoO}\right.$ and $\left.\mathrm{Co}_{3} \mathrm{O}_{4}\right)$, which appeared in this material due to the reasons previously indicated. On the other hand, the results concerning the B-K edge in Fig. 3a were applicable to the rest of the samples, according to the analyses of the $\mathrm{Co} \mathrm{L}_{2,3}$ edges. This means that $\mathrm{Co}\left(\mathrm{BO}_{2}\right)_{2}$ was formed after the catalytic test on the CoC coating, as well as $\mathrm{Co}_{\mathrm{x}} \mathrm{B}$ and oxides from $\mathrm{Co}$ and $\mathrm{CoB}$ coatings after the $\mathrm{SBH}$ hydrolysis. Comparing the three samples, the Co-C coating presented higher amount of Boron after its use, as it has been observed by the formation of $\mathrm{Co}_{\mathrm{x}} \mathrm{B}$ on its surface. This higher amount of this compound can be associated to the higher catalytic activity observed on this sample for 


\section{Acknowledgments}

\section{Conclusions}

In summary, this work performs the structural and compositional nanocharacterization of three potential catalysts deposited by MS on PTFE substrates. By the combination of different advanced (S)TEM techniques, the formation of nanoflake-like nanostructures onto the catalytic coatings after the catalytic test were analyzed, revealing a clear modification of the surface by the generation of nanoflakes. The compositional analyses pointed out the formation of $\mathrm{Co}_{\mathrm{x}} \mathrm{B}$ and B-oxides during the reaction, even $\mathrm{Co}\left(\mathrm{BO}_{2}\right)_{2}$ seems to be detected on $\mathrm{Co}-\mathrm{C}$ catalyst after its use. The formation of $\mathrm{Co}_{x} \mathrm{~B}$ nanoflakes at the surface explains the increase catalytic activity for the different analyzed catalysts, mainly for the Co-C catalysts. Details about the composition of the nanoflakes and remaining catalysts would help understand the mechanism of the catalytic reaction in future works and design new and more effective catalyst.

AMB thanks to Talent-Hub Program funded by the Junta de Andalucía and the European Commission under the Co-funding of the $7^{\text {th }}$ Framework Program in the People Program (Marie Curie Special Action). This work was supported by the Spanish MINECO (project CTQ2012-32519 and CTQ2015-65918) and Junta de Andalucía (PE2012-TEP862). AMB also acknowledge LANE-ICMS (CSIC, Spain) for the samples fabrication (Dr. V. Godihno), catalytic tests (Dr. G. Arzac), TEM samples preparation (Ms. Rosa.) and TEM facilities (Dr. A. Fernández). AMB thanks to M.C. for the fruitful discussion. 


\section{References}

${ }^{1}$ L.T Huang, A. Ali, H.H. Wang, F. Cheng, H.Y. Liu, Journal of Molecular Catalysis A:

Chemical 426 (2017) 213. DOI: 10.1016/j.molcata.2016.11.019

${ }^{2}$ H.Y. Kao, C.C. Lin, C.J. Hung, C.C. Hu, Journal of the Taiwan Institute of Chemical

Engineers 87 (2018) 123. DOI: 10.1016/j.jtice.2018.03.022.

${ }^{3}$ R.V. Engel, R. Alsaiari, E. Nowicka, P.J. Miedziak, S.A. Kondrat, D.J. Morgan, J.K. Edwards,

G.J. Hutchings, Catalysis Today, in press (2018). DOI: 10.1016/j.cattod.2018.09.005

${ }^{4}$ J. Lin, X. Meng, M. Zheng, B. Ma, Y. Ding, Applied Catalysis B: Environmental. 241 (2019)

351. DOI: 10.1016/j.apcatb.2018.09.052

${ }^{5}$ B.H. Davis. Ind. Eng. Chem. Res. 46 (2007)8938. DOI: 10.1021/ie0712434

${ }^{6}$ R. Luque, A.R. de la Osa, J.M. Campelo, A.A. Romero, J.L. Valverde, P. Sanchez, Energy

Environ. Sci. 5 (2012) 5186. DOI: 10.1039/C1EE02238E

${ }^{7}$ E.F. Sousa-Aguiar, F.B. Noronha, J.A. Faro Catal. Sci. Technol. 1 (2011) 698. DOI:

$10.1039 / \mathrm{c} 3 \mathrm{cy} 01021 \mathrm{j}$

${ }^{8}$ A. Zuttel, A. Borgschulte, L. Schlapbach Hydrogen as a Future Energy Carrier, ed., Wiley-

VCH (2008).

${ }^{9}$ U.B. Demirci, O. Akdim, J. Hannauer, R. Chamoun, P. Miele, Science China Chemistry 53

(2010) 1870. DOI: $10.1007 / \mathrm{s} 11426-010-4081-1$

${ }^{10}$ D.G. Tong, X. Han, W. Chen, H. Chen, X-Y. Ji, Materials Letters 61 (2007) 4679. DOI:

10.1016/j.matlet.2007.03.005

${ }^{11}$ Y. Han, Y. Wang, Y. Wang, L. Liao, H. Yuan, Int. J. Hydrogen Energy 35 (2010) 8177. DOI:

10.1016/j.ijhydene.2009.12.163

${ }^{12}$ D.G. Tong, W. Chu, P. Wu, L. Zhang, RSC Advances 2 (2012) 2369. DOI:

$10.1039 / \mathrm{c} 2 \mathrm{ra} 01321 \mathrm{e}$

${ }^{13}$ P.A. Krishnan, G. Suresh, A.K. Prasd, Appl. Catalysis B: Environmental 86 (2009) 137. DOI:

10.1016/j.apcatb.2008.08.005

${ }^{14}$ N. Patel, A. Miontello, Int. J. Hydrogen Energy 40 (2015) 1429.

DOI:dx.doi.org/10.1016/j.ijhydene.2014.11.052 
${ }^{15}$ A. Yousef, R.M. Brooks, M.M. El-Halwany, M. Obaid, M.H. E-Newehy, S.S. Al-Deyab, N.A.M. Barakat, Int. J. Hydrogen Energy 41 (2016) 285. DOI:

dx.doi.org/10.1016/j.ijhydene.2015.10.087

${ }^{16}$ T. Umegaki, Q. Xu, Y. Kojima, Materials 8 (2015) 4512. DOI: 10.3390/ma8074512

${ }^{17}$ M. Paladini, G.M. Arzac, V. Godinho, M.C. Jimenez de Haro, A. Fernández, Appl. Catalysis

B: Environmental 158-159 (2014) 400. DOI: http://dx.doi.org/10.1016/j.apcatb.2014.04.047 0926-3373

${ }^{18}$ J. Manna, B. Roy, M. Vashistha, P. Sharma, Int. J. Hydrogen Energy 39 (2014) 406. DOI: dx.doi.org/10.1016/j.ijhydene.2013.10.018

${ }^{19}$ Q. Wang, L. Jiao, H. Du, Q. Huan, W. Peng, D. Song, Y. Wang, H. Yuan, Electrochimica Acta 58 (2011) 437. DOI: 10.1016/j.electacta.2011.09.071

${ }^{20}$ M. Li, K.Y. Ma, J.P. Cheng, D. Lv,X.B. Zhang, J. of Power Sources 286 (2015) 438. DOI: http://dx.doi.org/10.1016/j.jpowsour.2015.04.013

${ }^{21}$ U.B. Demirci, P. Miele, Physical Chemistry Chemical Physics: PCCP 12 (2010) 14651. DOI: $10.1039 / \mathrm{c} 0 \mathrm{cp} 00295 \mathrm{j}$

${ }^{22}$ M. Paladini, M. Godinho, G.M. Arzac, M.C. Jimenez de Haro, A.M. Beltrán, A. Fernández, RSC Advances 6 (2016) 108611. DOI: 10.1039/c6ra23171c

${ }^{23}$ R. Arenal, F. de la Peña, O. Stéphan, M. Walss, M. Tencé, A. Loiseau, C. Colliex, Ultramicroscopy 109 (2008) 32. DOI: 10.1016/j.ultramic.2008.07.005

${ }^{24}$ P. Hartel, H. Rose, C. Dinges, Ultramicroscopy 63 (1996) 93.

${ }^{25} \mathrm{http} / / /$ www.gatan.com

${ }^{26}$ R. Messier, A.P. Giri, R.A. Roy, J. Vac. Sci. Technol., A 2 (1984) 500.

DOI:doi.org/10.1116/1.572604

${ }^{27}$ S.S. Muir, X. Yao, Int. J. Hydrogen Energy 36 (2011) 5983. DOI:

10.1016/j.ijhydene.2011.02.032

${ }^{28}$ N. Patel, R. Fernandes, G. Guella, A. Kale, A. Miotello, B. Patton, C. Zanchetta, J. Phys. Chem. C 112 (2008) 6969-6976 
${ }^{29}$ G.M. Arzac, T.C. Rojas, A. Fernández, Chem. Cat. Chem. 3 (2011) 1305. DOI: dx.doi.org/10.1002/cctc.201100101.

${ }^{30}$ Y. Zhu, R.F. Egerton, M. Malac, Ultramicroscopy 87 (2001) 135.

${ }^{31}$ Z. Zhang, Ultramicroscopy 107 (2007) 598. DOI: 10.1016/j.ultramic.2006.11.006 